\title{
Editorial
}

\section{Nobel Prize in Medicine 2020: Acknowledging the Discovery of Hepatitis C Virus}

\author{
Arka De ${ }^{1}$ Yogesh K. Chawla ${ }^{2}$ \\ ${ }^{1}$ Department of Hepatology, Postgraduate Institute of Medical \\ Education and Research, Chandigarh, Punjab, India \\ ${ }^{2}$ Kalinga Institute of Medical Sciences, Bhubaneshwar, Odisha, India
}

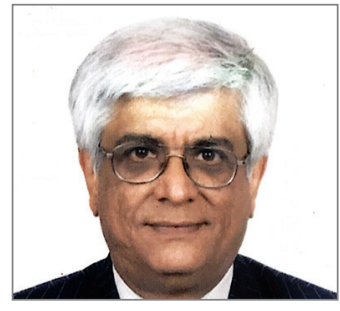

Yogesh K. Chawla

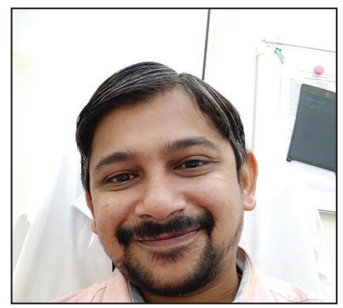

Arka De
The lack of motivation for research among young doctors has often been blamed to the suboptimal standards of medical research in general in India. The Nobel Prize in Medicine (Physiology) in 2020 has aroused great interest among doctors as it was awarded for the discovery of the hepatitis $\mathrm{C}$ virus (HCV)-a virus with substantial clinical significance. The painstaking and thorough research of the three Nobel laureates (Harvey J. Alter, Michael Houghton, and Charles M. Rice) ultimately paved the way for HCV from being an unknown entity to a curable viral infection in a short span of five decades. Their work revolutionized the fields of virology, immunology, and hepatology. ${ }^{1}$ The road to the discovery of the virus is a remarkable story of the triumph of passion, perseverance, and multifaceted, meticulous research. Acknowledgment of the discovery of the virus by the Noble Committee should encourage and motivate young doctors for going into research in their respective fields.

The journey into our understanding of HCV started almost five decades back in 1974 after the discovery of hepatitis A and hepatitis B in the preceding two decades. ${ }^{2}$ Harvey J. Alter and his team working at the Department of Blood Transfusion in the Bethesda center of National Institutes of Health, United States, noted that a substantial number of cases of posttransfusion hepatitis was not attributable to either hepatitis A or hepatitis B. Further, they demonstrated that this non-A non-B hepatitis could be transmitted to chimpanzees..$^{3-5}$ Their findings were corroborated by other teams and this transmissibility of disease pointed toward an infective agent. However, hopes of a rapid identification of the infective agent proved futile over the next 15 years and the virus eluded detection by the traditional techniques of microscopy, cell culture, and serology.
Molecular techniques were at its nascency and the adoption of this approach by Michael Houghton and his team at Chiron Corp., California, United States, ultimately led to the identification of the virus. The team at Chiron collaborated with Daniel Bradley of the Center of Disease Control and Prevention (CDC), Atlanta, United States, and developed a library of complementary deoxyribonucleic acid (cDNA) using samples obtained from chimpanzees infected with non-A non-B hepatitis. These were then transferred to bacteria and cloned using bacteriophages. The premise was that some of the proteins encoded by these cDNA would react with antibodies present in patients and chimpanzees infected with non-A non-B hepatitis. After years of painstaking research, the first such antigen epitope (corresponding to the viral envelope) was identified in 1989 from a clone called 5-1-1.6,7 This newly identified virus with a positive stranded ribonucleic acid (RNA) was named hepatitis $C$ and was subsequently classified as a Flavivirus. The novel methods adopted by Houghton drastically changed the field of virology and heralded a molecular revolution with the rapid identification of other viruses like hepatitis $G$ in the subsequent years.

By the beginning of the 1990s, researchers had discovered the modes of transmission of HCV, established its infectivity in chimpanzees, and unraveled its nuclear structure. However, whether infection with the virus alone was sufficient to cause clinically significant disease was yet unknown. The answer to this question came from the seminal work of Charles M. Rice and his team at Washington University, USA. They constructed a library of cDNA clones consisting of the

\section{Address for correspondence} Yogesh K. Chawla, MD, DM, FAMS, Kalinga Institute of Medical Sciences, Bhubaneshwar 751024, Odisha, India (e-mail: ykchawla@gmail.com).
DOI https://doi.org/ 10.1055/s-0040-1722381 ISSN 0379-038X. (c) 2020. National Academy of Medical Sciences (India).

This is an open access article published by Thieme under the terms of the Creative Commons Attribution-NonDerivative-NonCommercial-License, permitting copying and reproduction so long as the original work is given appropriate credit. Contents may not be used for commercial purposes, or adapted, remixed, transformed or built upon. (https://creativecommons.org/licenses/by-nc-nd/4.0/).

Thieme Medical and Scientific Publishers Pvt. Ltd. A-12, 2nd Floor, Sector 2, Noida-201301 UP, India 
3' untranslated region of the HCV genome and a consensus sequence. RNA transcribed from these cDNA clones was infective to chimpanzees and resulted in hepatitis. Thus, the link between $\mathrm{HCV}$ and liver disease was firmly established. ${ }^{8.9}$ In the new millennium, further granular understanding of viral biology including its life cycle was facilitated by the development of cell culture systems and the identification of a viral isolate that could infect human hepatoma cell lines. The construction of subgenomic viral replicons greatly aided the design and screening of targeted directly acting drugs. Indeed, research into HCV has now come full cycle with the advent of highly effective directly acting antivirals (DAAs) that can cure HCV in the vast majority of the patients.

Chronic HCV infection is among the predominant causes of cirrhosis and hepatocellular carcinoma and accounts for significant morbidity and mortality. The grim implications of a diagnosis of HCV can be construed from the fact that it is colloquially referred to as "kala piliya" (black or death jaundice) in North India. The World Health Organization estimates that globally there are 71 million people with chronic HCV infection. The viral prevalence in India is estimated to be 0.5 to $1 \%$ with regions of higher prevalences in the North East and Punjab. ${ }^{10}$ Fundamental research in HCV has had far reaching impacts in clinical practice. Knowledge of the modes of viral transmission and the development of methods for diagnostic methods led to the adoption of a policy of universal screening of blood donors which has led to a significant decrease in blood-borne viral transmission. Doctors and health care workers are well aware of the utility of universal safety precautions. Treatment of HCV had long been an unmet need. Treatment failures were frequent in the interferon era and adverse effects were common. Oral DAAs have revolutionized the management of $\mathrm{HCV}$ and is offering the hope of cure to millions of patients. The availability of pan-genotypic regimens precludes the need for pretreatment genotype testing, facilities for which are not widely available in resource-limited settings like India. Treatment of chronic HCV without prior genotype testing using pan-genotypic regimens has been shown to be effective and logistically feasible in Punjab under a program funded by the Mukh-Mantri Punjab Hepatitis C Relief Fund. ${ }^{11}$ This approach has now been endorsed by international authorities and has been extended to the whole of India under the National Viral Hepatitis Control Program.

The journey into the discovery of HCV holds several key lessons for any budding researcher. Identification of the problem is the first step in finding the solution. Indeed, recognition of the problem of non-A non-B hepatitis by Alter was the first step in the road to the discovery of HCV. Teamwork and a multifaceted, multidisciplinary approach is fundamental for delving deep into any problem. Professionally, Alter, Houghton, and Rice belonged to three fundamentally different yet related disciplines of medical research, namely clinical and epidemiological research, molecular biology, and virology. Passion, perseverance, and the spirit to accept failures are paramount for success in research. As discussed, the decade between the realization that non- $A$ non- $B$ hepatitis is caused by a transmissible agent and the identification of this agent as a novel virus was riddled with repeated failures. Lastly, the ability to draw logical conclusions is undeniably the most valued quality in a researcher.

The HCV success story is a testament to the remarkable potential of human endeavor. Indeed, from being a disease about which nothing was known until approximately five decades ago, the revolutionary work of these stalwarts has paved the way to easy diagnosis and treatment which is now making us think about the possibility of eliminating HCV by 2030 .

\section{Conflict of Interest}

None declared.

\section{References}

1 Press release: the Nobel prize in physiology or medicine 2020 [Internet]. Nobel Media AB; 2020. Available at: https:// www.nobelprize.org/prizes/medicine/2020/summary/. Accessed November 29, 2020

2 Baumert TF. The Nobel Prize in Medicine 2020 for the Discovery of Hepatitis C Virus: transforming hepatology. J Hepatol 2020;73(6):1303-1305

3 Alter HJ, Holland PV, Purcell RH, et al. Posttransfusion hepatitis after exclusion of commercial and hepatitis-B antigen-positive donors. Ann Intern Med 1972;77(5):691-699

4 Feinstone SM, Kapikian AZ, Purcell RH, Alter HJ, Holland PV. Transfusion-associated hepatitis not due to viral hepatitis type A or B. N Engl J Med 1975;292(15):767-770

5 Alter HJ, Purcell RH, Holland PV, Popper H. Transmissible agent in non-A, non-B hepatitis. Lancet 1978;1(8062) :459-463

6 Choo QL, Kuo G, Weiner AJ, Overby LR, Bradley DW, Houghton $M$. Isolation of a cDNA clone derived from a blood-borne non-A, non-B viral hepatitis genome. Science 1989;244(4902):359-362

7 Kuo G, Choo QL, Alter HJ, et al. An assay for circulating antibodies to a major etiologic virus of human non-A, non-B hepatitis. Science 1989;244(4902) :362-364

8 Kolykhalov AA, Feinstone SM, Rice CM. Identification of a highly conserved sequence element at the 3 ' terminus of hepatitis C virus genome RNA. J Virol 1996;70(6):3363-3371

9 Kolykhalov AA, Agapov EV, Blight KJ, Mihalik K, Feinstone SM, Rice CM. Transmission of hepatitis $C$ by intrahepatic inoculation with transcribed RNA. Science 1997;277(5325):570-574

10 Goel A, Seguy N, Aggarwal R. Burden of hepatitis C virus infection in India: a systematic review and meta-analysis. J Gastroenterol Hepatol 2019;34(2):321-329

11 Dhiman RK, Grover GS, Premkumar M, et al; MMPHCRF Investigators. Decentralized care with generic direct-acting antivirals in the management of chronic hepatitis $\mathrm{C}$ in a public health care setting. J Hepatol 2019;71(6):1076-1085 